\title{
A Meta-Analysis of Treatment Effects on Viral Pneumonia Using TCM Injections Specified in the Clinical Guideline for COVID-19 in China
}

\author{
Hea Sun Chun, Su Hyeon Choi, Ho Sueb Song* \\ Department of Acupuncture \& Moxibustion Medicine, College of Korean Medicine, Gachon University, Seongnam, Republic of Korea
}

Received September 3, 2021

Reviewed September 3, 2021

Accepted September 7, 2021

*Corresponding Author

Ho Sueb Song

Department of Acupuncture and

Moxibustion Medicine, College of Korean

Medicine, Gachon University, Seongnam

13120, Republic of Korea

Tel: +82-31-750-5424

E-mail: hssong70@gachon.ac.kr
Objectives: The purpose of this study is to analyze the efficacy of traditional Chinese medicine (TCM) injections specified in the clinical guideline for COVID-19 by conducting a meta-analysis of viral pneumonia data.

Methods: TCM injections data on viral pneumonia were collected until July 31, 2021. CNKI, PubMed, EMBASE, and the Cochrane electronic database were used to collect the clinical data. "COVID-19," "Viral pneumonia," "Tanreqing," "Xiyanping," "Reduning," "Xingnaojing," "Xuebijing," "Shenmai," "Shengmai," and "Shenfu" were used as keywords. All data collected were mainly about TCM injections and viral pneumonia. Furthermore, studies that included results such as the total effective rate, cough disappearance time, antipyretic time, lung rhomboid disappearance time, and adverse drug reaction were collected for the meta-analysis to identify the efficacy of TCM injections. However, data unrelated to TCM injections specified in the clinical guidelines for COVID-19 or viral pneumonia were excluded. The quality of included RCTs was assessed by the Cochrane Risk of Bias Tool, and Review Manager 5.3 software was used to conduct the meta-analysis.

Results: A total of 18 studies with 1540 patients were included in this study. The results of the meta-analysis showed that the total effective rate $\mathrm{OR}=4.61(95 \% \mathrm{Cl} 2.92,7.25, \mathrm{p}$ $\left.=1.00 / \mathrm{I}^{2}=0 \%\right)$; the cough disappearance time: SMD $-1.23(-1.37,-1.09, \mathrm{p}<0.00001 /$ $\left.\mathrm{I}^{2}=94 \%\right) ;$ the antipyretic time: SMD $-1.26\left(-1.40,-1.11, \mathrm{p}<0.00001 / \mathrm{I}^{2}=94 \%\right)$; lung rhomboid disappearance time: SMD $-1.17\left(-1.33,-1.02, p<0.00001 / \mathrm{I}^{2}=89 \%\right)$; and adverse drug reaction was OR $0.36\left(95 \% \mathrm{Cl} 0.20,0.64, \mathrm{p}=0.21 / \mathrm{I}^{2}=30 \%\right)$. From the results, the treatment group (TCM injection) showed better efficacy than the control group (Western medication).

Conclusion: Xiyanping, Reduning, and Tanreqing injections may yield benefits as COVID-19 treatments. However, clinical trials on TCM injections for the treatment of COVID-19 are still lacking. More high-quality clinical trials are still required.

Keywords: covid-19, sars-cov-2, viral pneumonia, tcm injection

\section{INTRODUCTION}

The novel coronavirus 2019 (COVID-19) caused by severe acute respiratory syndrome coronavirus-2 (SARS-CoV-2) was first reported in Wuhan, Hebei Province, China in 2019. Then, in 2020, the situation becomes serious worldwide. On March 11, 2020, the World Health Organization (WHO) designated the COVID-19 outbreak as a pandemic [1]. COVID-19 spreads relatively easily due to its strong contagiousness, and wild animal hosts and infected patients are the main causes of infection [2]. Johns Hopkins University (JHU) reported that more than 200 million people have been infected with COVID-19 so far [3], and more than 200,000 people have been infected in Korea [4]. To prevent the infection and spread of COVID-19, the production of personal protective equipment (PPE) not only in Korea but also around the world has increased, and measures 
to cope with the disease while emphasizing the importance of social distancing, wearing masks, and vaccines have also been emphasized. However, the constant outbreaks of COVID-19 are still causing social and economic chaos as well as adverse health effects [5].

When confirmed with COVID-19, patient treatment is mainly focused on symptomatic treatment such as antipyretics, fluid supply, antitussives, and oxygen in the case of shortness of breath [6]. In particular, there is a lack of research related to the treatment of COVID-19 using Chinese medicine injections. However, in China, it was found that research on COVID-19 related to the use of herbal medicines and Chinese medicine injections is still in progress. In addition, for the treatment of COVID-19 in China, the National Health Commission of China announced the Novel Coronavirus Treatment Plan as an enforcement decree. According to the severity of a case, Xiyanping (喜炎平), Reduning (熱毒寧), Tanreqing (痰熱淸), Xuebijing (血必淨), and Xingnaojing (醒腦靜) injections were administered. Reduning (熱毒寧), Tanreqing (痰熱淸), Xuebijing (血必淨), Xingnaojing (醒腦靜), Shenfu (參參), and Shengmai (生脈) have been designated as treatment drugs for seriously ill patients [7].

However, there is still a lack of clinical research data on COVID-19-related Chinese medicine injections, so we conducted a study to determine the treatment effects and side effects of using Chinese medicine injections by analyzing existing viral pneumonia clinical studies targeting the Chinese medicine injections specified in the treatment plan. Although the medical environments in China and Korea are different, there is a limit to directly studying neutral medicine and Chinese medicine injections in Korea. The purpose of this study is to prepare basic data for Korean oriental medicine research and the use of herbal medicines by comparing the effects of treatment cases.

\section{MATERIALS AND METHODS}

\section{Literature review}

Based on the electronic databases for documents published up to July 2021, this study used "Xiyanping," "Reduning," "Tanreqing," "Xingnaojing," "Xuebijing," and "Shenmai" as the search keywords in CNKI, PubMed, EMBASE, and Cochrane. "Shengmai," "Shenfu," "Viral Pneumonia," and "COVID-19" were also used for the search.

\section{Paper selection method}

1) Randomized controlled trials (RCTs), 2) "Novel Coronavirus Treatment Plan 8th Edition" published by the National Health Commission of China, 3) eight types of Chinese medicine injections specified in the Enforcement Decree (Xiyanping, Reduning, Tanreqing, Xuebijing, Xingnoajing, Shenfu, Shenmai, and Shengmai), and 4) studies related to viral pneumonia and COVID-19 were the selection criteria. All original texts in Chinese or English were included in the study without limiting for gender, age, etc. In addition, from the entire contents of the original texts selected through the primary screening task, the original texts with specifications regarding the recovery period for the clinical results, specifically 1) effectiveness, 2) cough, 3) fever, 4) pulmonary crackle, or other side effects, applied to the study subjects were included. Through the screening of titles and abstracts, original texts, animal experiments, and other interventions other than traditional Chinese medicine injections were included in the intervention group. Clinical texts that were not RCTs, clinical texts specified in the top list among the entire contents of the original texts selected after primary screening, and original texts that did not include results or did not specify side effects were excluded.

\section{Paper analysis method}

The results were analyzed by dividing the final included texts into the recovery period and side effects for each symptom, such as effective rate, cough, fever, and pulmonary crackling, according to the clinical results. The analysis results of side effects included gender, age, treatment method, treatment period, incidence of side effects, and side effects symptoms. As a statistical analysis method, meta-analysis was performed through Review Manager 5.3. The odds ratio (OR) was used for the analysis of the efficacy rate and side effects, and the results regarding the recovery period for all symptoms were calculated using standard mean difference (SMD). For all data, heterogeneity was judged through $\mathrm{I}^{2}$ and $\mathrm{p}$ values based on $95 \%$ confidence intervals (Cis), and when $\mathrm{I}^{2} \leq 50 \%$ and $\mathrm{p}>0.05$, heterogeneity was judged to be low. When $\mathrm{I}^{2}>50 \%$ and $\mathrm{p} \leq$ 0.05 , heterogeneity was judged to be high. Cochrane risk of bias (RoB) was used to evaluate the quality of the study, and a total of six items-1) generate random assignment order, 2) hide assignment order, 3) blindfold (research participants, researchers, outcome evaluations), 4) insufficient result data, 5) selective 
reporting, 6) other biases-were analyzed. In addition to the literature database, the "Chinese Pharmacopoeia" [9] and the drug search database [10] were used to collect information on the study, such as the pharmacological effects, ingredients, and applied conditions of Chinese medicine injections.

\section{RESULTS}

\section{Search results}

In the search for related literature, only the original texts containing the eight Chinese medicine injection types for COVID-19 treatment and viral pneumonia were selected. CNKI 151, PubMed 27, and EMBASE 7 yielded a total of 192 original texts by July $31^{\text {st }}, 2021$. Version 7 of Cochrane was also searched. Among them, original texts not related to Chinese medicine injections $(\mathrm{n}=6)$, animal experiments $(\mathrm{n}=6)$, and Chinese medicine injections in the intervention group through the primary screening of titles and abstracts yielded 190 original texts except for two duplicated texts that included other interventions $(\mathrm{n}=89)$ and non-RCT texts $(\mathrm{n}=36)$. A total of 137 original texts were excluded because they did not fit the purpose of this study. Among the 53 selected original texts, 18 original texts with specific indications regarding the clinical results related to 1) efficacy, 2) cough, 3) fever, and 4) recovery period for pulmonary crackle or side effects were included as the final analysis target. Thirty-five original texts that were not published were excluded (Fig. 1).

\section{Research content by type of Chinese medicine injection}

This study was conducted to analyze the effects of traditional Chinese medicine injections and Western medicine injections on viral pneumonia. In the intervention group, Chinese medicine injections were used, and in the control group, Western medications commonly used for viral pneumonia were used as the standard. Among the 1,540 patients, the ages ranged from 3-month-old infants to 78-year-old elderly, and both Reduning and Tanreqing injections were used for pediatric patients under 10 years of age with viral pneumonia. In terms of gender, there were 771 males and 568 females with a higher proportion of males than females ( $p>0.05$ ), and Xiyanping, Reduning, and Tanreqing all showed a higher proportion in males than females. The frequency of administration was once a day the most, but in some cases, it was administered once or twice a

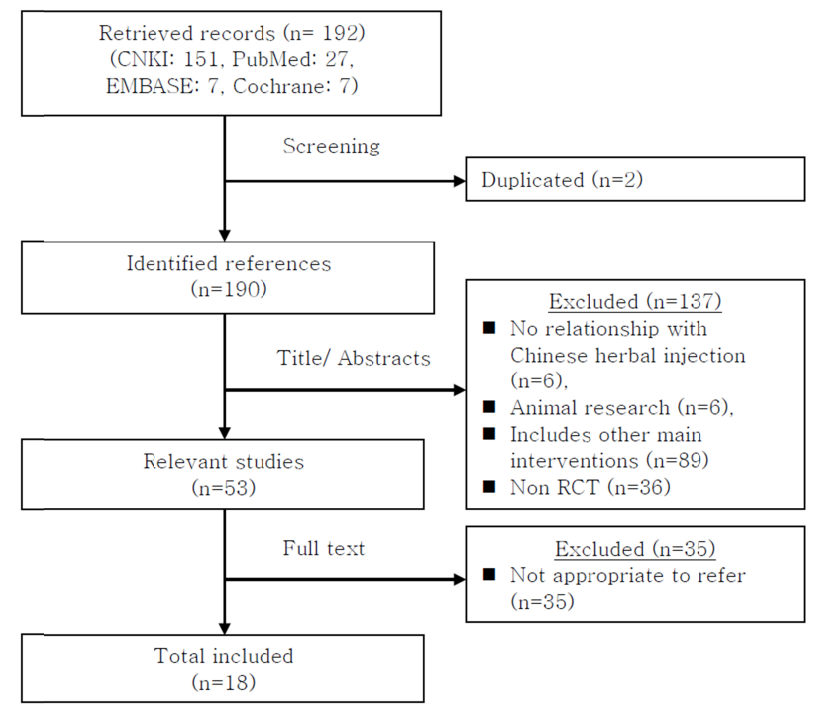

Figure 1. Flow chart.

day.

The most common treatment period was 7 days, and treatment was continued for as little as 5 days and up to 10 days. All injections were administered by intravenous Ringer, and the injection dose was $0.2-20 \mathrm{mg} / \mathrm{kg}$ for pediatric patients under 10 years old and 1-400 mg/kg for patients over 10 years old. As a diluent, $5 \%$ glucose was most often used, and $0.9 \%$ sodium chloride solution was also used. In the case of side effects from the Chinese medicine injection, 17 out of 334 people in the intervention group had side effects, and among them, nausea/ vomiting and skin rash symptoms were the most common. In the comparison group, ribavirin injection was used the most, and there was also a comparison group that used oseltamivir phosphate. In the comparison group, a single dose of ribavirin was $10-15 \mathrm{mg} / \mathrm{kg}$, and in the case of oseltamivir phosphate, 2 $\mathrm{mg} / \mathrm{kg}$ was used. As a diluent, $0.5 \%$ and $5 \%$ glucose were used. In the comparison group, side effects such as nausea/vomiting, skin rash, adverse liver reactions, WBC adverse reactions, dyspnea, and chest pain occurred in 37 out of a total of $292 \mathrm{pa}-$ tients, and $12.67 \%$ had adverse drug reactions (Table 1).

\section{Effectiveness}

Among the 13 clinical datasets, there were Xiyanping [6, 11-18], Reduning [3, 19-21], and Tanreqing injections [2, 22, 23] that could be divided into names. Effectiveness was found in 481 out of 507 intervention patients, and in 401 out of 499 patients in the control group, effectiveness was shown. ORs 
Hea Sun Chun, et al.

Table 1. Basic characteristics of meta analysis

\begin{tabular}{|c|c|c|c|c|}
\hline Classification & Xiyanping $(n=365)$ & Reduning $(n=272)$ & Tanreqing $(n=158)$ & Total $(n=795)$ \\
\hline Age & $3 \mathrm{~m}-78 \mathrm{y}$ & $4 \mathrm{~m}-9.4 \mathrm{y}$ & $6 m-8 y$ & $3 m-78 y$ \\
\hline \multicolumn{5}{|l|}{ Sex } \\
\hline Male & 408 & 184 & 179 & 771 \\
\hline Female & 294 & 144 & 130 & 568 \\
\hline Duration & $7-10 \mathrm{~d}(1 / \mathrm{d})$ & $5-7 d(1-2 / d)$ & $5-7 d(1 / d)$ & $5-10 d(1-2 d)$ \\
\hline Injection type & IV (Ringer) & IV (Ringer) & IV (Ringer) & IV (Ringer) \\
\hline \multicolumn{5}{|l|}{ Usage } \\
\hline$\geq 10 y$ & $0.2-10 \mathrm{mg} / \mathrm{kg}$ & $0.5-20 \mathrm{mg} / \mathrm{kg}$ & $0.3-0.5 \mathrm{mg} / \mathrm{kg}$ & $0.2-20 \mathrm{mg} / \mathrm{kg}$ \\
\hline$<10 y$ & $20-400 \mathrm{mg} / \mathrm{kg}$ & - & $1-20 \mathrm{mg} / \mathrm{kg}$ & $1-400 \mathrm{mg} / \mathrm{kg}$ \\
\hline Diluent & $5 \% \mathrm{GL}, 0.9 \% \mathrm{SC}$ & $5 \% G L$ & $5 \% \mathrm{GL}$ & $5 \% \mathrm{GL}, 0.9 \% \mathrm{SC}$ \\
\hline ADR & $9 / 90(10 \%)$ & 6/154 (3.9\%) & $2 / 90(2.22 \%)$ & 17/334 (5.09\%) \\
\hline Diarrhea/vomit & $9 / 90(10 \%)$ & - & - & $9 / 90(10 \%)$ \\
\hline Skin & - & 6/154 (3.9\%) & $2 / 90(2.22 \%)$ & 8/244 (3.28\%) \\
\hline $\mathrm{OM}$ & $(\mathrm{T} / \mathrm{C})$ & $(\mathrm{T} / \mathrm{C})$ & $(\mathrm{T} / \mathrm{C})$ & $(\mathrm{T} / \mathrm{C})$ \\
\hline TER & $275 / 269$ & $164 / 164$ & $68 / 66$ & $507 / 499$ \\
\hline CDT & $275 / 269$ & $164 / 164$ & $68 / 66$ & $507 / 499$ \\
\hline APT & $275 / 269$ & $164 / 164$ & $68 / 66$ & $507 / 499$ \\
\hline LRDT & $213 / 208$ & $115 / 115$ & $68 / 66$ & $396 / 389$ \\
\hline ADR & $90 / 78$ & $154 / 154$ & $90 / 60$ & $334 / 292$ \\
\hline Control usage & $\operatorname{RBV}(n=347)$ & OST/RBV $(n=272)$ & $\operatorname{RBV}(n=126)$ & OST/RBV $(n=745)$ \\
\hline$\geq 10 y$ & $10-15 \mathrm{mg} / \mathrm{kg}$ & $\begin{array}{r}2 \mathrm{mg} / \mathrm{kg}(2 / \mathrm{d}) / \\
10-15 \mathrm{mg} / \mathrm{kg}\end{array}$ & $10-15 \mathrm{mg} / \mathrm{kg}$ & $\begin{array}{r}2 \mathrm{mg} / \mathrm{kg}(2 \mathrm{~d}) / \\
10-15 \mathrm{mg} / \mathrm{kg}\end{array}$ \\
\hline$<10 y$ & $10-500 \mathrm{mg} / \mathrm{kg}$ & - & - & $10-500 \mathrm{mg} / \mathrm{kg}$ \\
\hline Diluent & $0.5 \% \mathrm{GL}, 5 \% \mathrm{GL}$ & $5 \% \mathrm{GL}$ & $5 \% \mathrm{GL}$ & $0.5 \% \mathrm{GL}, 5 \% \mathrm{GL}$ \\
\hline ADR & $8 / 78(10.2 \%)$ & 19/154 (12.33\%) & $10 / 60(16.66 \%)$ & $37 / 292(12.67 \%)$ \\
\hline Diarrhea/vomit & $8 / 78(10.2 \%)$ & 8/154 (5.20\%) & $6 / 60(10 \%)$ & 24/292 (8.22\%) \\
\hline Skin & - & 5/154 (3.25\%) & - & $5 / 154$ (3.25\%) \\
\hline Liver & - & 4/154 (2.60\%) & $1 / 60(1.66 \%)$ & $5 / 214(2.34 \%)$ \\
\hline WBC & - & 2/154 (1.30\%) & $1 / 60$ (1.66\%) & $3 / 214$ (1.4\%) \\
\hline RSP/chest & - & - & $2 / 60$ (3.33\%) & $2 / 60$ (3.33\%) \\
\hline
\end{tabular}

T, Treatment Group; C, Control Group; OM, Outcome Measurement; RBV, Ribavirin Injection; IV, Intravenous (Ringer); GL, Glucose; SC, Sodium Chloride; OST, Oseltamivirphosphate; TER, Total Effective Rate; CDT, Cough Disappearance Time; APT, Antipyretic Time; LRDT, Lung Rhomboid Disappearance Time; ADR, Adverse Drug Reaction; RSP, Respiratory.

were used to analyze the effects on the intervention and control groups, and OR was 4.61 (95\% CI 2.92, 7.25, $\mathrm{p}=1.00 / \mathrm{I}^{2}=0 \%$ ). The value of $\mathrm{I}^{2}$ was less than $50 \%$ and $\mathrm{p}>0.05$, so it was judged that heterogeneity was low, and the intervention group was more effective at $94.872 \%$, which is $14.511 \%$ higher than the effective rate of $80.361 \%$ of the control group (Table 2, 3, Fig. 2).

\section{Symptom recovery period}

In this study, to analyze the treatment effects of different drugs on viral pneumonia, effectiveness was determined by the presence or absence of symptoms of pneumonia, such as cough, fever, and pulmonary crackling. First, regarding the cough symptom recovery period, Xiyanping [8, 11-18], Reduning [3, 19-21], and Tanreqing injections $[2,22,23]$ were used in 13 clinical datasets. These datasets were further divided 


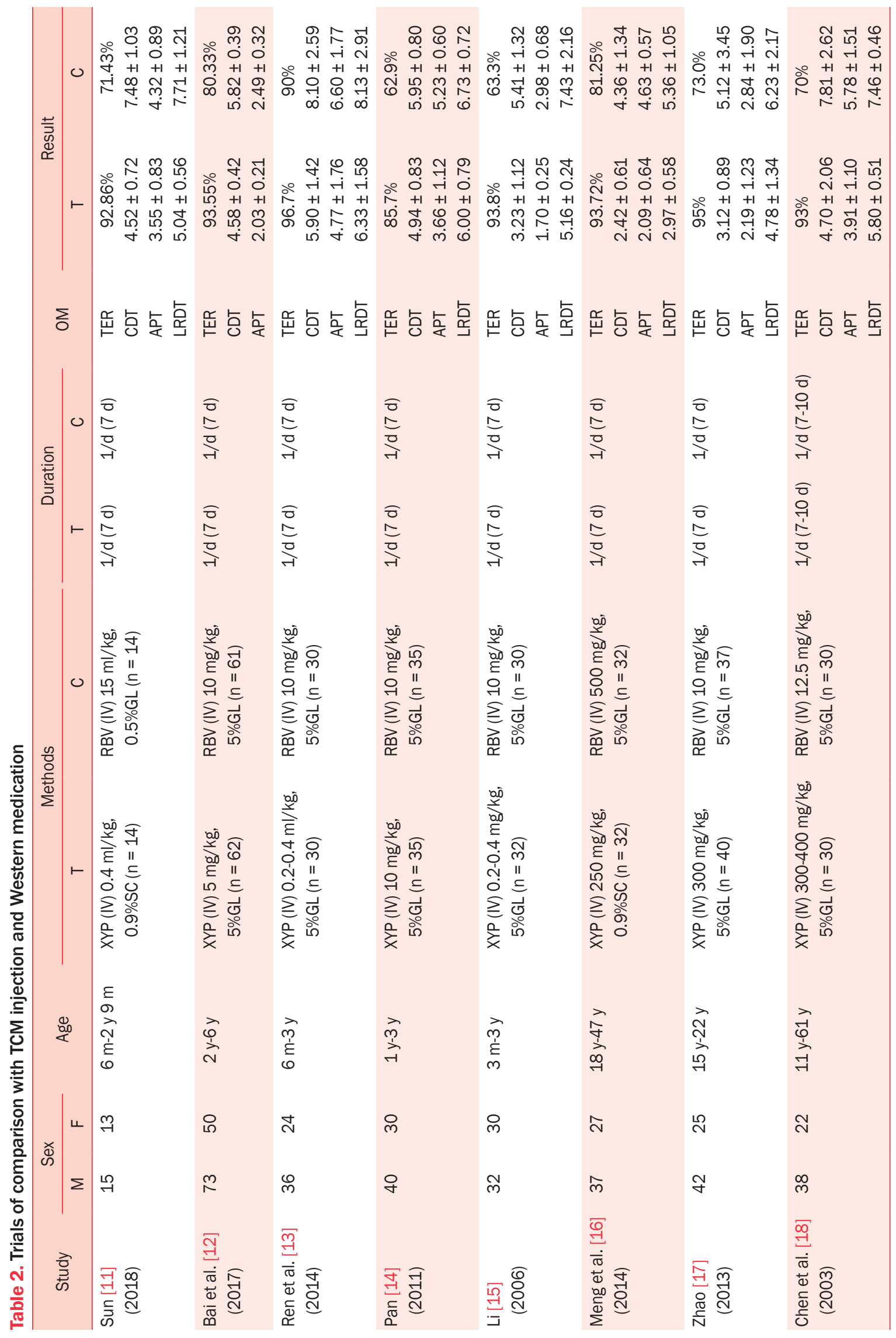




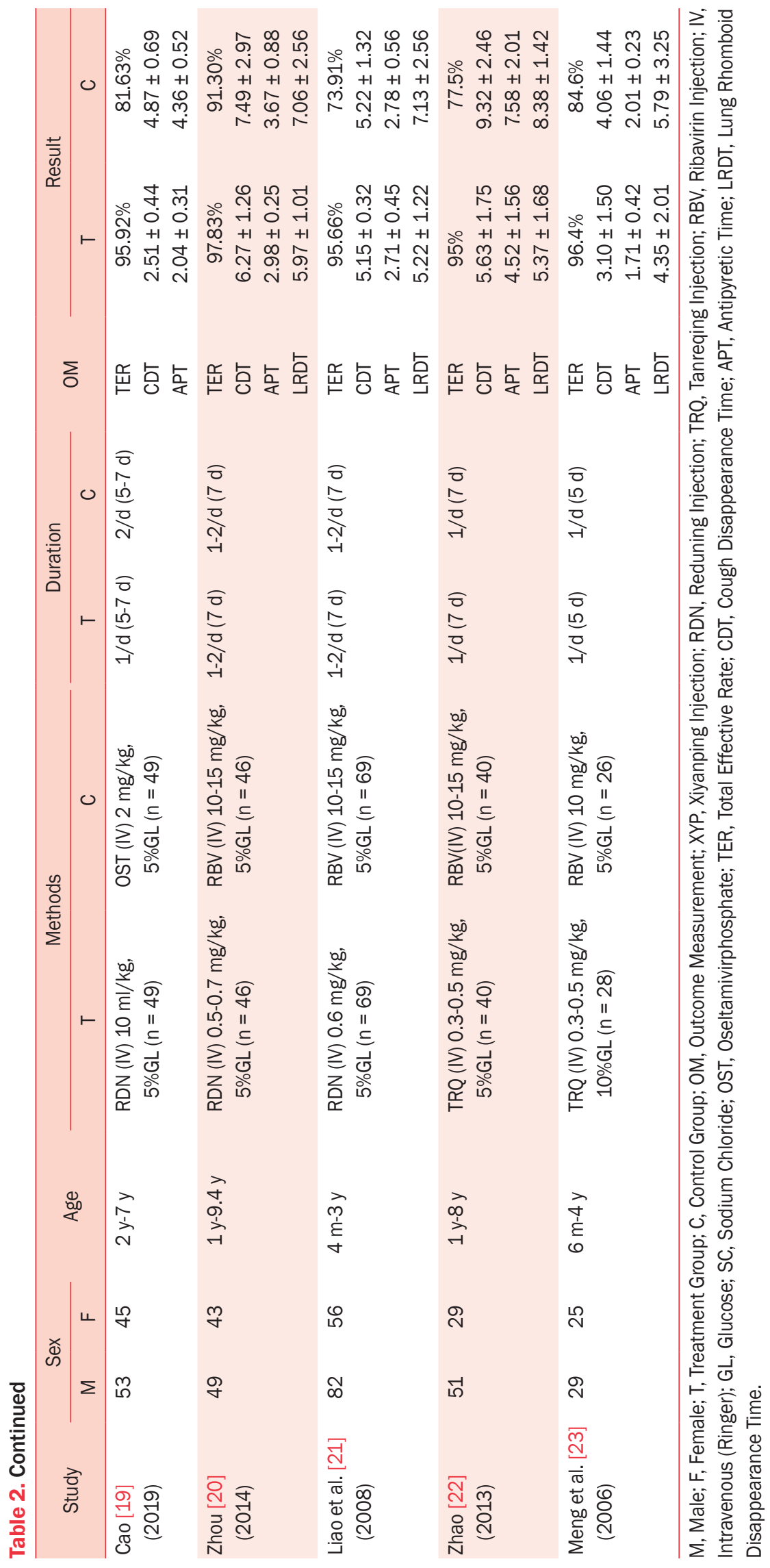


Table 3. The results of meta analysis of included studies

\begin{tabular}{cccccccc}
\hline $\begin{array}{c}\text { Outcome } \\
\text { measurement }\end{array}$ & $\begin{array}{c}\text { Number of } \\
\text { study }\end{array}$ & $\begin{array}{c}\text { Sample size } \\
(\mathrm{T} / \mathrm{C})\end{array}$ & Measures & Effect estimate (95\%Cl) & Heterogeneity & $p$ & Included studies \\
\hline TER & 13 & $507 / 499$ & OR & $4.61[2.92,7.25]$ & $\mathrm{I}^{2}=0 \%$ & 1.00 & {$[11-23]$} \\
CDT & 13 & $507 / 499$ & SMD & $-1.23[-1.37,-1.09]$ & $\mathrm{I}^{2}=94 \%$ & $<0.00001$ & {$[11-23]$} \\
APT & 13 & $507 / 499$ & SMD & $-1.26[-1.40,-1.11]$ & $\mathrm{I}^{2}=94 \%$ & $<0.00001$ & {$[11-23]$} \\
LRDT & 11 & $396 / 389$ & SMD & $-1.17[-1.33,-1.02]$ & $\mathrm{I}^{2}=89 \%$ & $<0.00001$ & {$[11,13-18,20-23]$} \\
ADR & 6 & $334 / 292$ & OR & $0.36[0.20,0.64]$ & $\mathrm{I}^{2}=89 \%$ & 0.21 & {$[20,24-28]$} \\
\hline
\end{tabular}

TER, Total Effective Rate; CDT, Cough Disappearance Time; APT, Antipyretic Time; LRDT, Lung Rhomboid Disappearance Time; ADR, Adverse Drug Reaction.

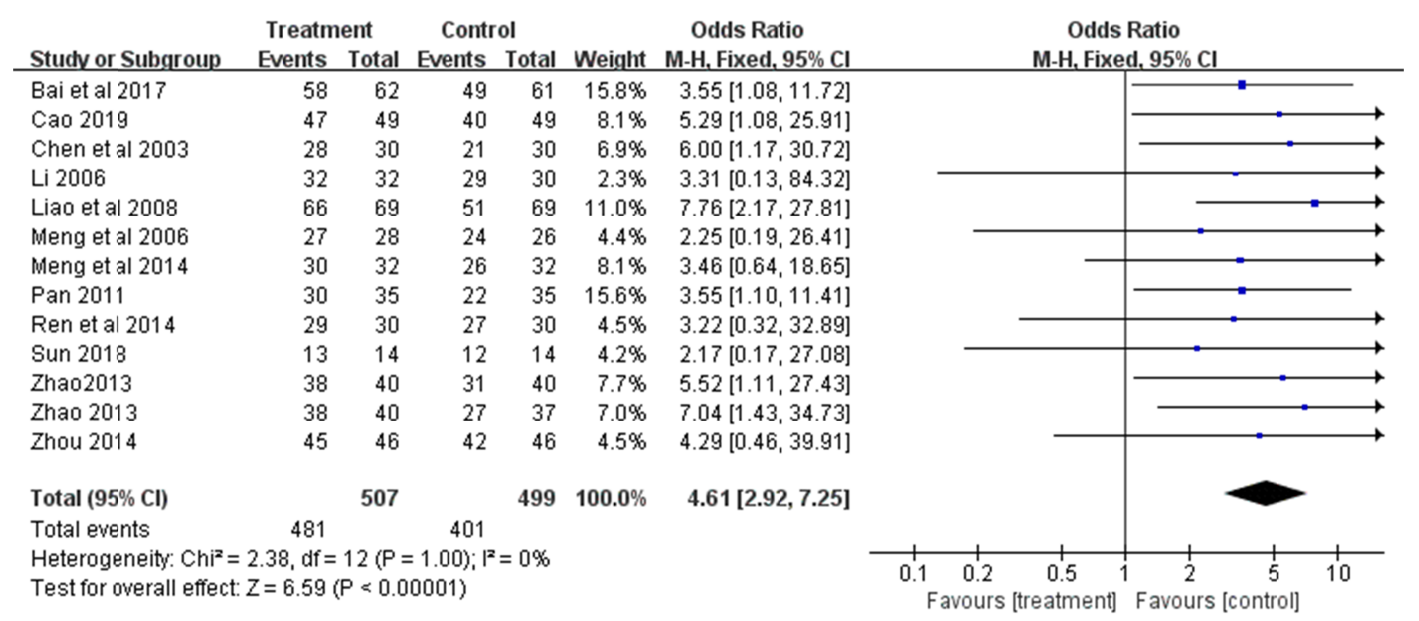

Figure 2. Total effective rate of TCM injections and Western medications for viral pneumonia.

into 507 patients in the intervention group and 499 patients in the control group. SMD was used to analyze the effects on the intervention group and the control group, and the result was SMD $=-1.23\left(-1.37,-1.09, \mathrm{p}<0.00001 / \mathrm{I}^{2}=94 \%\right)$. The value of $\mathrm{I}^{2}$ was $50 \%$ or more and $\mathrm{p} \leq 0.05$, so it was judged that the heterogeneity was high, but it was found that the intervention group showed a more significant result than the control group because one was not included in the confidence estimate.

In the fever symptom recovery period, as in the cough symptom recovery period, Xiyanping [8, 11-18], Reduning [3, 19$21]$, and Tanreqing $[2,22,23]$ injections were used, and a total of 1006 patients' data were collected in the intervention group, while 507 and 499 patients' data were collected in the control group. SMD was used to analyze the effects on the intervention and control groups, and the results showed SMD was -1.26 $\left(-1.40,-1.11, \mathrm{p}<0.00001 / \mathrm{I}^{2}=94 \%\right)$. The value of $\mathrm{I}^{2}$ was $50 \%$ or more and $\mathrm{p} \leq 0.05$, so it was judged that the heterogeneity was high, but it was found that the intervention group showed a more significant result than the control group because one was not included in the confidence estimate. Finally, in the recovery period for the pulmonary crackle sound, there were seven $\mathrm{Xi}$ yanping [11, 13-18], Reduning [2, 20, 21], and Tanreqing [2, 22, 23 ] injections, and a total of 785 patients' data were collected from 396 patients in the intervention group, and the control group could be divided into 389 patients.

SMD was used to analyze the effects on the intervention and control groups, and the results showed SMD was $-1.17(-1.33$, $\left.-1.02, \mathrm{p}<0.00001 / \mathrm{I}^{2}=89 \%\right)$. The value of $\mathrm{I}^{2}$ was $50 \%$ or more and $\mathrm{p} \leq 0.05$, so it was judged that heterogeneity was high, but one was not included in the confidence estimate (Figs. 3-5).

\section{Side Effects}

Among the six clinical datasets, there were Xiyanping [1, 24], Tanreqing [2, 25, 26], and Reduning [3, 20, 27, 28] injections that could be divided into names. Side effects occurred in 17 of 334 patients in the intervention groups. Among them, 9 of 90 patients injected with Xiyanping showed diarrhea [24], and 2 of 
Hea Sun Chun, et al.

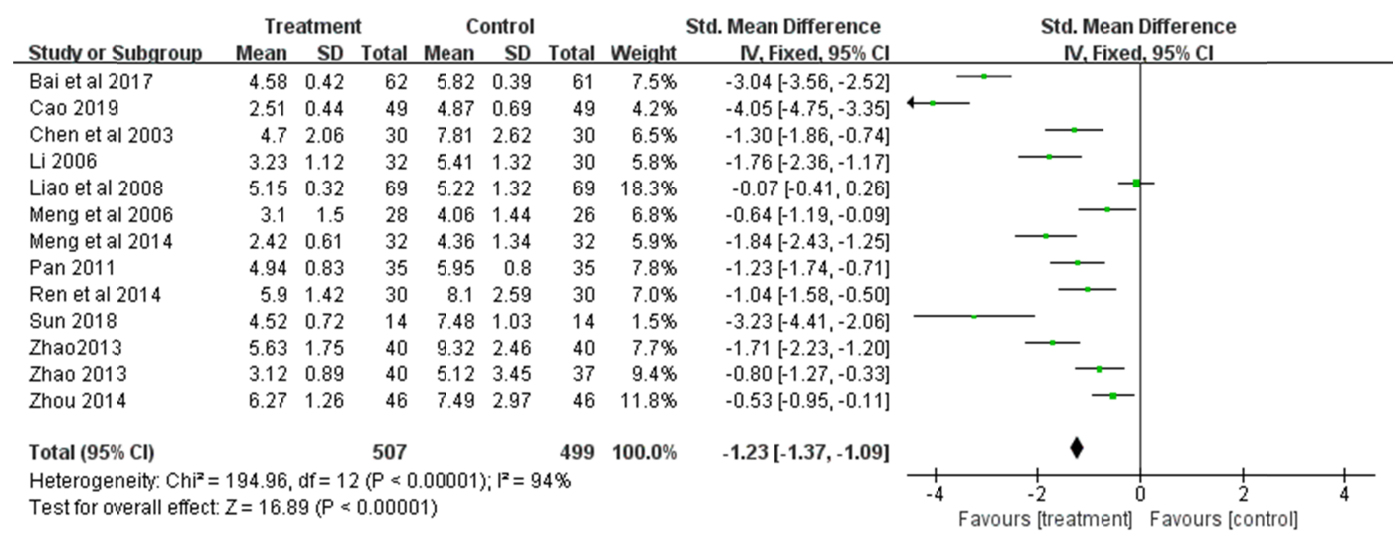

Figure 3. Cough disappearance time of TCM injections and Western medications for viral pneumonia.

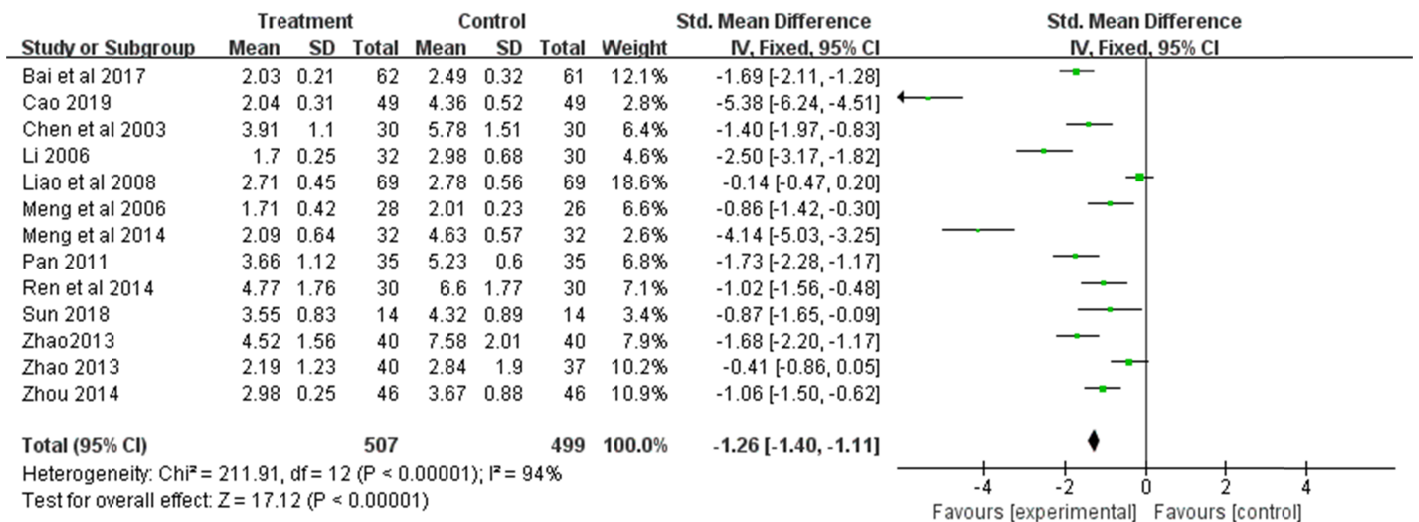

Figure 4. Antipyretic time of TCM injections and Western medications for viral pneumonia.

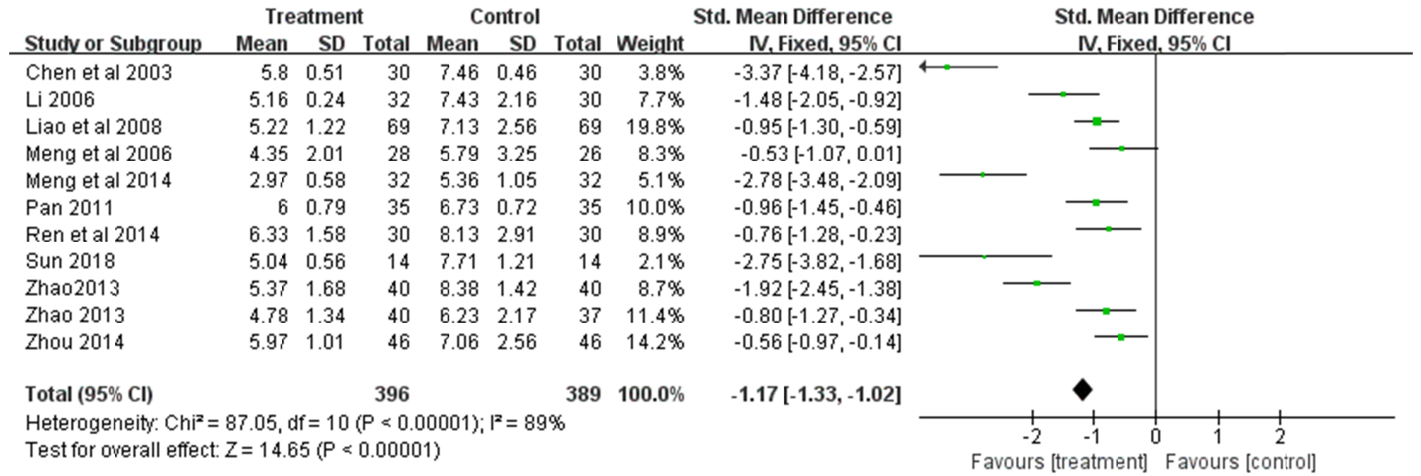

Figure 5. Lung rhomboid disappearance time of TCM injections and Western medications for viral pneumonia.

90 patients injected with Tanreqing showed skin rash $[25,26]$. Reduning injection showed skin rash symptoms in 6 out of 154 patients [20, 27, 28].

In the comparison group, side effects occurred in 39 of 292 patients. All 39 patients used ribavirin injections. Nausea/vomiting occurred in 24 cases, skin rash occurred in 5 cases, liver ad- verse reactions occurred in 5 cases, leukocyte adverse reactions occurred in 3 cases, and dyspnea and chest pain occurred in 2 cases. ORs were used to analyze the effects on the intervention and control groups, and OR was 0.36 (95\% CI 0.20, 0.64, p = $\left.0.21 / \mathrm{I}^{2}=30 \%\right)$. The value of $\mathrm{I}^{2}$ was less than $50 \%$ and $\mathrm{p}>0.05$, so it was judged that heterogeneity was low (Table 3, 4, Fig. 6). 


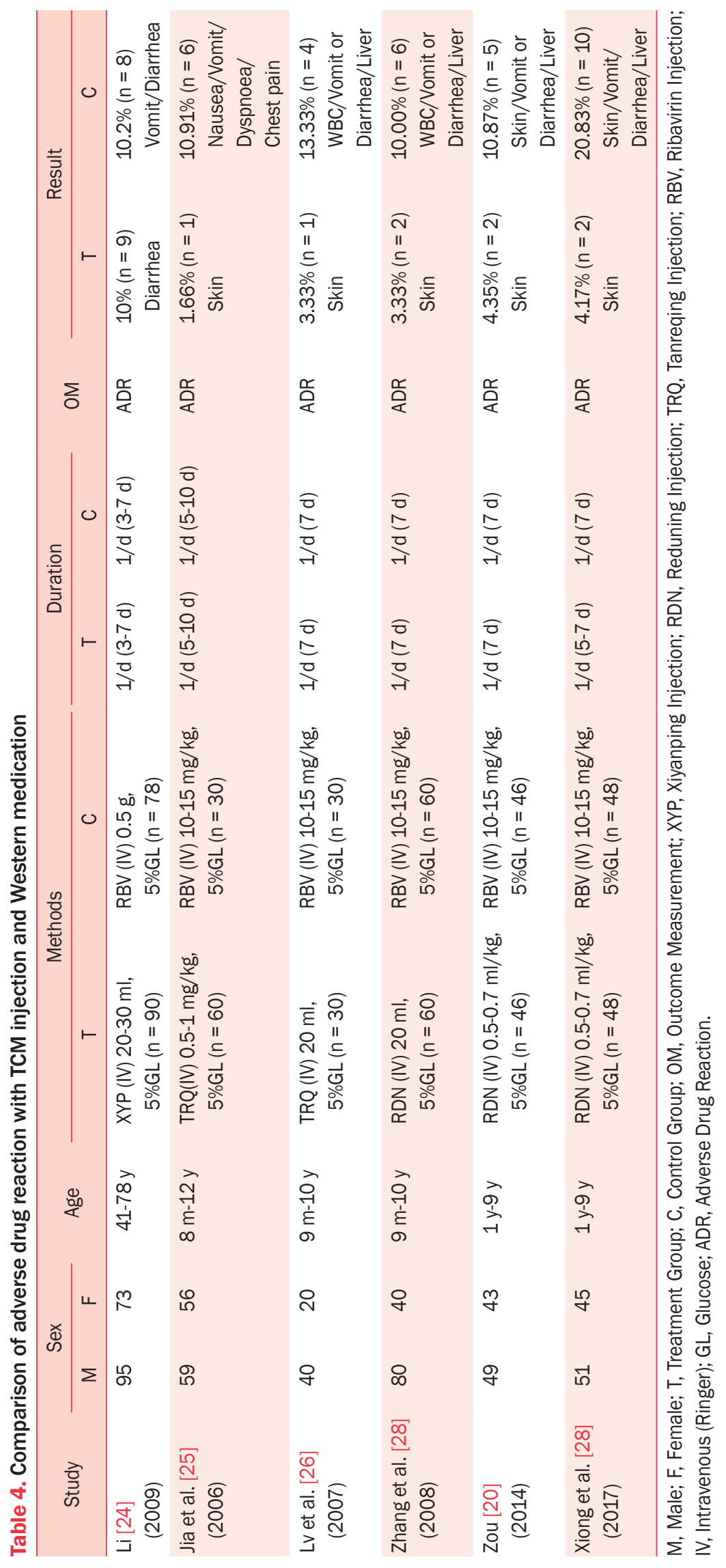




\section{Evaluation of Research Quality}

The quality of the study was analyzed by dividing the 18 clinical datasets into six items. To evaluate the randomization order generation, all 18 clinical datasets were organized using the randomization order method, but among them, two datasets $[13,18]$ used the random number table method, so the evaluation of bias was judged to be low, and 14 datasets [11, 12, 14, 16-19, 21-28] used a RCT method, but there was no men- tion of the order of assignment. In two datasets $[15,20]$, the evaluation of bias was judged to be high because the allocation method according to the order of admission and the even and odd number method according to the patient registration number were used. There was no mention of concealment of assignment order, insufficient result data, selective reporting, or other biases, and the evaluation of bias was judged to be high because blinding was not performed in the course of the study (Fig. 7, 8).

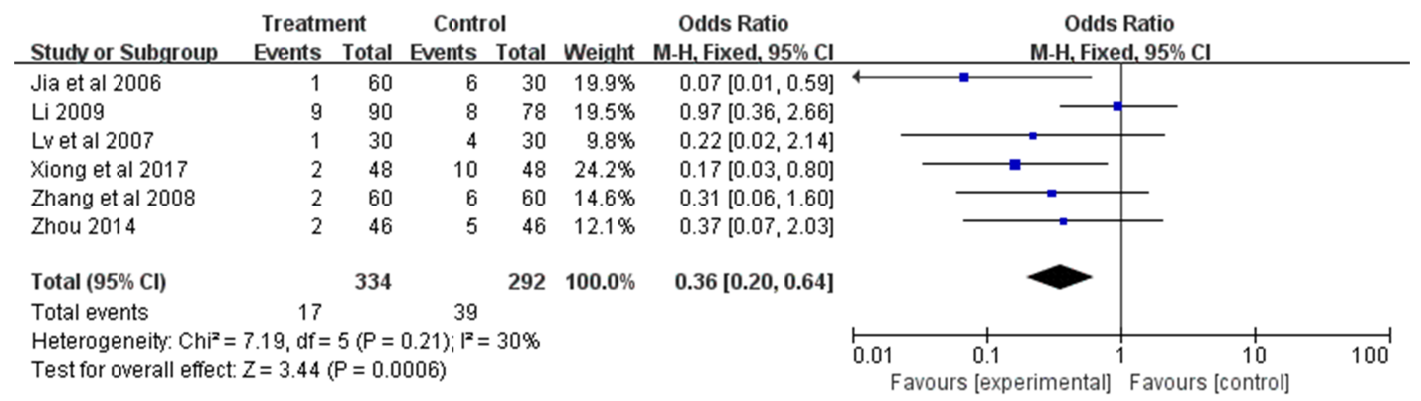

Figure 6. Adverse drug reaction of TCM injections and Western medications for viral pneumonia.

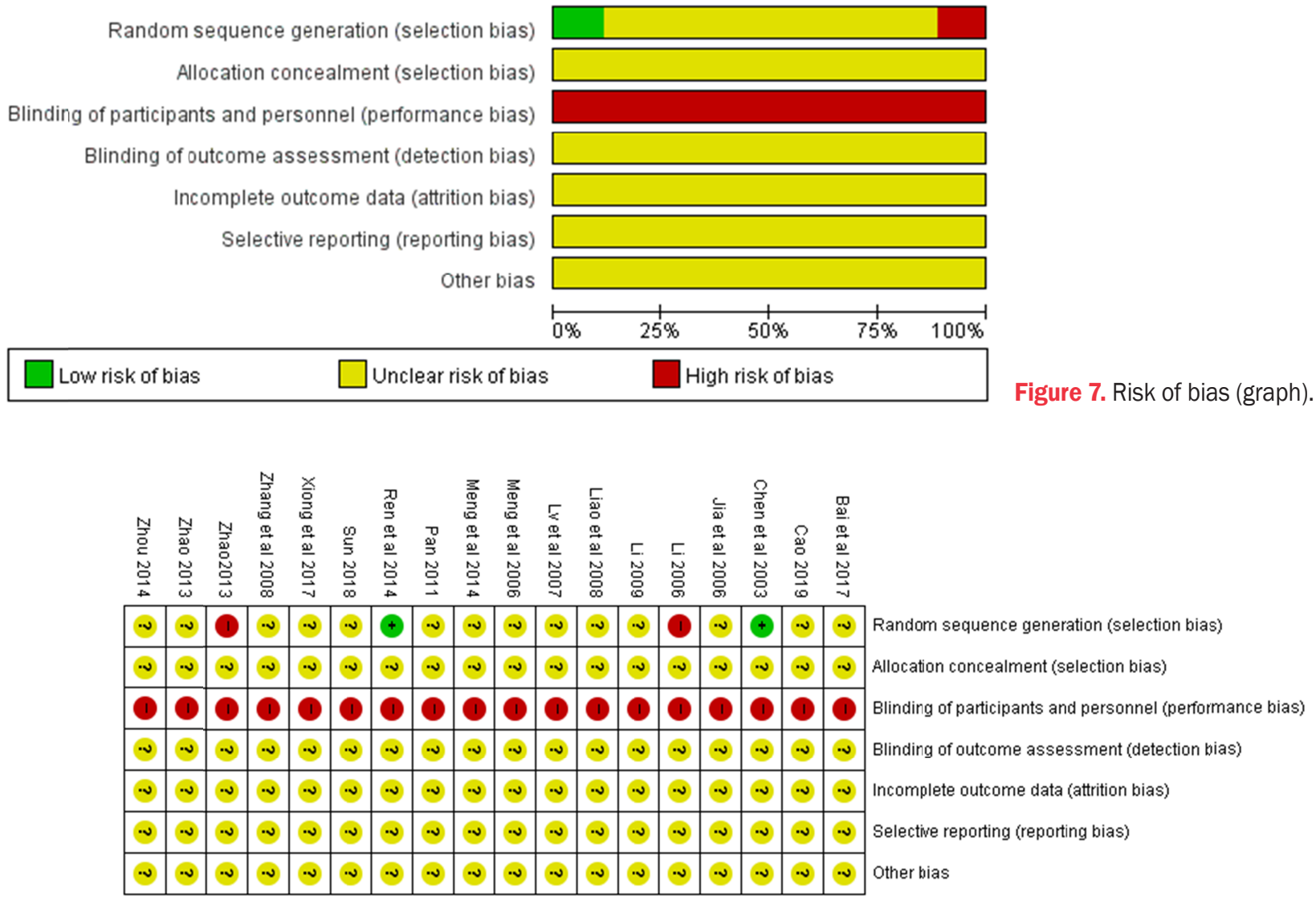

Figure 8. Risk of bias (summary). 


\section{REVIEW}

Chinese medicine injections are an injection-type Chinese medicine preparation, and it is expressed faster in the body compared to existing oral medicine preparations such as decoctions, pills, and granules [29]. As they are highly effective against infections, they play an important role in the Chinese herbal medicine market [30]. According to the COVID-19 treatment plan recently announced by the National Health Commission of China, treatment methods for COVID-19 have been divided into traditional Chinese medicine treatments according to the severity of the disease and traditional Western medicine treatments. Some neutral medicines, including Chinese medicine injections, were recommended as treatments for COVID-19 [8].

Treatment plans can be divided into four categories: mild, moderate, severe, and dangerous according to symptoms (Table 5) [31]. In the case of Chinese medicine injections, they are mainly recommended for use in the severe or dangerous categories of patients. According to this, a basic treatment was made for Chinese constipation. Among them, Xiyanping (喜炎 平) injection is used for severe cases, and Reduning (熱毒寧), Tanreqing (痰熱清), Xuebijing (血必淨), and Xingnaojing (醒 腦靜) injections are all used for the severe or dangerous categories. Shenfu (參附), Shengmai (生脈), and Shenmai (參麥) injections are recommended for use in the risk stage [8].

Therefore, this research conducted a clinical study to determine the actual therapeutic effects of traditional Chinese medicine injections on COVID-19. However, there is still a lack of clinical research data on Chinese medicine injections for COVID-19, so this study was conducted to analyze the therapeutic effects of Chinese medicine injections specified in the COVID-19 treatment plan for the treatment of viral pneumonia. Symptoms of COVID-19 mainly consist of coughing, shortness of breath, and fever, and patients who test positive for COVID-19-related pneumonia are reported to be accompanied by high fever and persistent cough [32]. It was reported that the basic symptoms are very similar to the general symptoms of influenza virus, and in severe cases, ground glass opacity (GGO) appears in the periphery of the lungs on both sides of a chest computed tomography (CT) image [33].

In this study, based on the symptoms of cough, shortness of breath, and fever, which are the basic symptoms of pneumonia, the recovery time for each symptom was divided into an intervention group (Chinese medicine injection) and a control group (Western drug treatment) to determine the significance of the treatment effect. The benefit of treatment was judged by comparing the effectiveness and side effects of the intervention group and the control group. In Korea, acupuncture therapy is a treatment method similar to traditional Chinese medicine injections, but unlike Korean acupuncture therapy, which deals only with herbal medicines, in China, various preparations are used under the name of Chinese medicine injections, regardless of whether they are herbal preparations or Western medicine preparations $[34,35]$. Although Korea and China have similar forms of treatment, it can be seen that they are used in independent development methods according to the treatment environment. In Korea, there is still no oriental medical intervention method designated by the country as that in China, and research on oriental medicine interventions related to COVID-19 is still in progress. As such, it is difficult to find COVID19-related research data on herbal medicine use.

Table 5. Clinical classification of COVID-19

\begin{tabular}{ll}
\hline Classification & \multicolumn{1}{c}{ Criteria } \\
\hline Mild & Mild clinical symptoms; no sign of pneumonia on imaging \\
Moderate & Fever and respiratory symptoms with radiological findings of pneumonia \\
Severe & 1. Respiratory distress ( $\geq 30$ breaths/min) \\
& 2. Oxygen saturation $\leq 93 \%$ at rest \\
& 3. $\mathrm{PaO}_{2} / \mathrm{FiO}_{2} \leq 300 \mathrm{mmHg}$, In high-altitude areas $(\geq 1,000 \mathrm{~m}), \mathrm{PaO}_{2} / \mathrm{FiO}_{2}$ shall be corrected as: \\
& $\mathrm{PaO}_{2} / \mathrm{FiO}_{2} \times$ [atmospheric pressure (mmHg) $\left./ 760\right]$ \\
& Cases with chest imaging that shows obvious lesion progression within $24-28 \mathrm{hr}>50 \%$ shall be managed as \\
& severe cases. \\
Critical & 2. Respiratory failure and requiring mechanical ventilation \\
& 2. Shock \\
3. With other organ failure that requires ICU care
\end{tabular}


Although there is a limit to the direct application of research on neutral medicine and Chinese medicine injections in Korea due to the difference in the medical environment between China and Korea, based on previous research data in China, the types and efficacies of Chinese medicine injections used to treat COVID-19 and viral pneumonia were compared in this study. The comparison of the effects of treatment cases was conducted because it was determined that basic data could be prepared for future Korean medical research and the utilization of herbal medicines.

There are eight types of Chinese medicine injections specified in the COVID-19 treatment plan in China, and Xuebijing (血必淨), Xingnaojing (醒腦靜), Shenfu (參附), Shengmai (生 脈), and Shenmai (參麥) appeared in the literature search. It was difficult to find clinical data related to viral pneumonia and injections, and in the case of Xuebijing injection, although there were related clinical data, it was excluded as it was judged inappropriate to include other Western medicine intervention groups apart from Chinese medicine injections in the intervention group.

The final dataset included Xiyanping, Reduning, and Tanreqing injections, which all had a therapeutic effect on the detoxification of fever. Xiyanping injection is used for conditions such as bronchitis, tonsillitis, and bacterial dysentery. It is also used to treat colds and coughs, upper respiratory infections, and acute bronchitis caused by the Tanreqing injection. It was found to be used for diseases such as chronic bronchitis and upper respiratory tract infections [9]. Regarding the use of Chinese medicine injections, in the treatment plan, Xiyanping, Reduning, and Tanreqing injections are used for viral and mild bacterial infections. Xiyanping injection at $100 \mathrm{mg}$ b.i.d., Reduning injection at $20 \mathrm{ml}$, or Tanreqing injection at $40 \mathrm{ml}$ bid is diluted with $0.9 \%$ sodium chloride $250 \mathrm{ml}$, which was recommended [8].

In addition, Xingnaojing injection is recommended for high fever accompanied by impaired consciousness. Xuebijing injection is recommended for systemic inflammatory reaction syndrome or organ function impairment. Shenmai or Shengmai injection is recommended for immunosuppression. 腦開窺 was judged to be used for disorders of consciousness. Xuebijing was found to have an effect of detoxifying live fish and was recommended considering the characteristics used for conditions such as systemic inflammatory reaction syndrome.

In addition, shock can occur at the risk stage of COVID-19. Therefore, Shenmai, Shengmai, and Shenfu are effective in maintaining yang and yin in the body and are effective in improving shock and immune function. It was found to be effective and recommended (Table 6) [9]. However, as this study focused on the clinical study of the treatment of viral pneumonia, the purpose of this study was to determine improvements in symptoms such as cough, fever, and pulmonary crackling. There are limitations to the study.

According to the collected data, many clinical studies on pediatric viral pneumonia patients were reported, and as a result of analysis by age, the smallest age ranged from a 3-month-old infant to a maximum of 78 years old. The treatment period was mainly 5-10 days, and all injections were intravenous (Ringer's) injections. As for the dose, it was found that $0.2-20 \mathrm{mg} / \mathrm{kg}$ was administered to patients under 10 years of age, and 1-400 mg/ $\mathrm{kg}$ was administered to patients over 10 years of age. However, it can be seen that this is an overall numerical value, and the result value is relative. The dosage for each injection varied according to the age and condition of the patient.

In the case of the diluent, $5 \%$ glucose solution or $0.9 \%$ sodium chloride solution was used, but the use of $0.9 \%$ sodium chloride was recommended in clinical practice. Ribavirin, which is an antiviral drug that has the effect of inhibiting viral enzymes involved in viral nucleic acid synthesis, was used the most in the control group. It is used in combination with interferon injection [36].

In this study, a total of 18 clinical datasets were divided into symptom improvement, efficacy rate, and side effects. There were 13 clinical datasets on efficacy rate, cough, and fever symptom recovery period, 11 datasets on pulmonary symptom recovery period, and six clinical datasets related to side effects.

First, as a result of the effectiveness rate analysis of the intervention group and the control group, the OR was 4.61 (95\% CI $2.92,7.25, \mathrm{p}=1.00 / \mathrm{I}^{2}=0 \%$ ), which was judged to be low according to the $\mathrm{I}^{2}$ and $\mathrm{p}$ values. A $94.872 \%$ effective rate for the intervention group showed that the intervention group had higher efficacy than the control group at $80.361 \%$.

Next, by analyzing the results of the intervention and control groups regarding the symptom recovery times for cough, fever, and pulmonary crackles, which are symptoms of pneumonia, improvement in cough symptoms showed SMD was -1.23 $\left.(-1.37,-1.09, \mathrm{p}<0.00001] . / \mathrm{I}^{2}=94 \%\right)$. According to the $\mathrm{I}^{2}$ and $\mathrm{p}$ values, heterogeneity was judged to be high, but the confidence estimate did not include one, so it was found that the intervention group showed a more significant result than the control group. 
Table 6. Basic drug characteristics of TCM injections for COVID-19

\begin{tabular}{|c|c|c|c|c|}
\hline Status & Injections & Efficacy & Target diseases & Ingredient \\
\hline Severe & Xiyanping & $\begin{array}{l}\text { Heat clearing and detoxification } \\
\text { (Qingre-jiedu) }\end{array}$ & $\begin{array}{l}\text { Bronchitis, Tonsillitis, } \\
\text { Bacillary dysentery, etc }\end{array}$ & Andrographolide, Sulfonate \\
\hline \multirow[t]{4}{*}{ Severe/critical } & Reduning & $\begin{array}{l}\text { Heat clearing and detoxification } \\
\text { (Qingre-jiedu) }\end{array}$ & $\begin{array}{l}\text { Cold, Cough (wind-heat); } \\
\text { Upper respiratory infection; } \\
\text { Acute Bronchitis }\end{array}$ & $\begin{array}{l}\text { Artemisiae Annuae, } \\
\text { Gardeniae Fructus, } \\
\text { Lonicerae Flos }\end{array}$ \\
\hline & Tanreqing & $\begin{array}{l}\text { Heat clearing and detoxification } \\
\text { (Qingre-jiedu) }\end{array}$ & $\begin{array}{l}\text { Pneumonia, Acute Bronchitis, } \\
\text { Chronic Bronchitis } \\
\text { Upper respiratory infection }\end{array}$ & $\begin{array}{l}\text { Scutellariae Radix, Lonicerae } \\
\text { Flos, Fel Ursi powder, } \\
\text { Forsythiae Fructus }\end{array}$ \\
\hline & Xingnaojing & $\begin{array}{l}\text { Heat clearing and detoxification; } \\
\text { Restoring Consciousness } \\
\text { (Xingnao-kaiqiao) }\end{array}$ & $\begin{array}{l}\text { Cerebral Embolism; } \\
\text { Acute Cerebral Hemorrhage } \\
\text { Craniocerebral Trauma } \\
\text { Acute Alcoholism }\end{array}$ & $\begin{array}{l}\text { Artificial Moschus, } \\
\text { Gardeniae Fructus, } \\
\text { Borneolum Syntheticum, } \\
\text { Curcumae Radix }\end{array}$ \\
\hline & Xuebijing & $\begin{array}{l}\text { Blood regulating and Detoxification } \\
\text { (Huayu-jiedu) }\end{array}$ & $\begin{array}{l}\text { Systemic Inflammatory Response } \\
\text { Syndrome induced by infection; } \\
\text { Multiple Organ Dysfunction } \\
\text { Syndrome }\end{array}$ & $\begin{array}{l}\text { Cnidii Rhizoma, } \\
\text { Salviae Miltiorrhizae, } \\
\text { Carthami Flos, } \\
\text { Paeoniae Radix Rubra, } \\
\text { Angelicae Gigantis Radix }\end{array}$ \\
\hline \multirow[t]{3}{*}{ Critical } & Shenfu & $\begin{array}{l}\text { Restoring Yang-qi (Huiyang-jiuni); } \\
\text { Tonifying Qi (Buyi) }\end{array}$ & $\begin{array}{l}\text { Shock; Palpitation; Cough; } \\
\text { Stomachache; Arthritis, etc }\end{array}$ & Red Ginseng, Aconitine \\
\hline & Shenmai & $\begin{array}{l}\text { Tonifying Qi and Preventing } \\
\text { Exhaustion (Yiqi-gutuo); } \\
\text { Nourishing Yin-qi (Yangyin) }\end{array}$ & $\begin{array}{l}\text { Shock; Coronary Heart Disease; } \\
\text { Viral Myocarditis; } \\
\text { Granulocytopenia (Can improve } \\
\text { the Immune function) }\end{array}$ & Red Ginseng, Liriopis Tuber \\
\hline & Shengmai & $\begin{array}{l}\text { Tonifying Qi and Preventing } \\
\text { Exhaustion (Yiqi-gutuo); } \\
\text { Nourishing Yin-qi (Yangyin) }\end{array}$ & $\begin{array}{l}\text { Palpitation; Shortness of Breath; } \\
\text { Myocardial Infarction; } \\
\text { Cardiogenic Shock; } \\
\text { Septic Shock, etc }\end{array}$ & $\begin{array}{l}\text { Red Ginseng, Liriopis Tuber, } \\
\text { Schisandrae Fructus }\end{array}$ \\
\hline
\end{tabular}

The improvement in fever symptoms showed SMD was $-1.26\left(-1.40,-1.11, \mathrm{p}<0.00001 / \mathrm{I}^{2}=94 \%\right)$, the value of $\mathrm{I}^{2}$ was $50 \%$ or more, and $\mathrm{p} \leq 0.05$, so it was judged that heterogeneity was high. One was not included, so it could be seen that the intervention group showed a significant result compared to the control group. Finally, the result value for the improvement in pulmonary bullous noise showed SMD was $-1.17(-1.33,-1.02$, $\left.\mathrm{p}<0.00001 / \mathrm{I}^{2}=89 \%\right)$. The improvement in lung symptoms was also judged to have high heterogeneity, but it was found that the intervention group showed a more significant result than the control group because one was not included in the confidence estimate.

In the occurrence of side effects, the analysis results of the intervention and control groups showed OR $=0.36(95 \% \mathrm{CI}$ $\left.0.20,0.64, \mathrm{p}=0.21 / \mathrm{I}^{2}=30 \%\right)$, the $\mathrm{I}^{2}$ value was less than $50 \%$, and $\mathrm{p}>0.05$, so there was no heterogeneity. It was judged to be low, and $5.090 \%$ of the intervention group showed a more sig- nificant result in the intervention group, as it was $8.27 \%$ lower than that of $13.356 \%$ of the control group.

Based on the results of the analyzed data, the intervention group showed effective improvements in symptoms compared to the control group, and the incidence of side effects was significantly lower than that of both drugs. Therefore, Xiyanping, Reduning, and Tanreqing injections are effective in treating fever, cough, and the lungs, and furthermore, when symptoms of COVID-19 appear, they are also expected to be effective in improving the same symptoms such as fever, cough, and lungs.

However, in the quality evaluations of this study, there was no mention of randomization sequence creation, hiding of allocation sequences, insufficient result data, selective reporting, and other biases. Therefore, higher quality clinical studies should be conducted in the future. In this study, due to the lack of clinical data related to Chinese medicine injections for COVID-19, a meta-analysis was conducted for the clinical study of 
viral pneumonia. The further accumulation of research data is necessary.

\section{CONCLUSION}

Through this study, it was found that in China, not only conventional Western medicines but also several neutral medicines, including traditional Chinese medicine and Chinese medicine injections, are recommended as a COVID-19 treatments. Types of injections used for COVID-19 treatments include Xiyanping, Tanreqing, and Reduning for viral pneumonia, improvement of fever, and cough and lung symptoms. Side effects related to clinical research analysis were used to determine the therapeutic effects and safety of Chinese medicine injections for symptom improvement of COVID-19. It is expected that this study can be used as basic data to increase the usability of acupuncture and herbal medicines in the future.

\section{CONFLICT OF INTEREST}

The authors declare no conflicts of interest.

\section{ORCID}

Hea Sun Chun, https://orcid.org/0000-0002-1002-9312

Su Hyeon Choi, https://orcid.org/0000-0001-7389-1949

Ho Sueb Song, https://orcid.org/0000-0001-5306-8795

\section{REFERENCES}

1. World Health Organization. Coronavirus Disease (COVID-19) Pandemic [Internet]. Geneva: World Health Organization; c2021 [cited 2020 Mar 11]. Available from: https://www.who.int/ emergencies/diseases/novel-coronavirus-2019.

2. Shi Y, Wang G, Cai XP, Deng JW, Zheng L, Zhu HH, et al. An overview of COVID-19. J Zhejiang Univ Sci B. 2020;21(5):34360 .

3. COVID-19 Dashboard by the Center for Systems Science and Engineering (CSSE) at Johns Hopkins University (JHU) [Internet]. Baltimore (MD): Johns Hopkins University \& Medicine; c2021 [cited 2021 Aug 15]. Available from: https://coronavirus. jhu.edu/map.html.

4. COVID-19 [Internet]. Sejong: Ministry of Health and Welfare; [cited 2021 Aug 1]. Available from: http://ncov.mohw.go.kr/.

5. Li Y, Tenchov R, Smoot J, Liu C, Watkins S, Zhou Q. A comprehensive review of the global efforts on COVID-19 vaccine development. ACS Cent Sci. 2021;7(4):512-33.

6. Zhai P, Ding Y, Wu X, Long J, Zhong Y, Li Y. The epidemiology, diagnosis and treatment of COVID-19. Int J Antimicrob Agents. 2020;55(5):105955.

7. Zeng CY, Cao HL, Mei CX. Key points for rational use and drug monitoring of traditional Chinese medicine injections in the COVID-19 diagnosis and treatment scheme (trial version 7). China Pharm. 2020;23(5):878-83.

8. National Medical Health Office. [2021] 191. Novel Coronavirus Pneumonia Diagnosis and Guideline (Trial Version 8, Revised Version) [Internet]. Beijing: The General Office of National Health Commission Office of State TCM Administration; 2021 Apr 15 [cited 2021 Aug 30]. Available from: http://www.nhc.gov. cn/yzygj/s7653p/202104/7de0b3837c8b4606a0594aeb0105232b. shtml. Chinese.

9. State Pharmacopoeia Committee of China. [Chinese pharmacopoeia]. Beijing: The Medicine Science and Technology Press of China; 2020. Chinese.

10. Yao ZH [Internet]. Zhongqing: YAOZH.COM; c2009-2021 [cited 2021 Jul 10]. Available from: www.yaozh.com. Chinese.

11. Sun RJ. [Therapeutic effect of Xiyanping Injection on viral pneumonia in children]. Cardiovasc Dis J Integr Tradit Chin West Med. 2018;6(4):62. Chinese.

12. Bai TM, Da CS. Curative effect of Xiyanping injection in the treatment of children with viral pneumonia. Shaanxi J Tradi Chin Med. 2017;38(10):1354-5.

13. Ren ZD, Bao YB, Xu HB. [Clinical efficacy of Xiyanping injection in the treatment of infantile viral pneumonia]. China J Pharm Econ. 2014;Suppl 1:169-70. Chinese.

14. Pan YR. [Therapeutic effect of Xiyanping Injection on 35 cases of viral pneumonia in children]. Chin Pediatr Integr Tradit West Med. 2011;3(5):415-6. Chinese.

15. Li YJ. [Therapeutic effect of Xiyanping on viral pneumonia in children]. Qingdao Med J. 2006;38(3):176-7. Chinese.

16. Meng Z, Pei LW. [Effect analysis of Xiyanping in the treatment of viral pneumonia]. J Clin Med Lit. 2014;1(11):1938-9. Chinese.

17. Zhao WL. [Effect of Xiyanping in the treatment of viral pneumonia]. J North Pharm. 2013;10(12):40-1. Chinese.

18. Chen JY, Zhao MS, Cao XH. [Clinical observation of Xiyanping injection in the treatment of viral pneumonia]. J Binzhou Med Coll. 2003;26(3):217-8. Chinese.

19. Cao SB. [Effect of Reduning Injection on viral pneumonia in children]. Chin J Clin Ration Drug Use. 2019;12(34):113-4. Chinese.

20. Zou WK. [Effect of Reduning Injection on viral pneumonia in children]. Contemp Med Forum. 2014;12(21):167-9. Chinese.

21. Liao YZ, Guo WZ, Lu SY. [Clinical observation of Reduning Injection in the treatment of viral pneumonia in children]. Chin J 
Mod Drug Appl. 2008;2(19):34-5. Chinese.

22. Zhao RF. [Clinical observation of Tanreqing Injection in the treatment of viral pneumonia in children]. J Emerg Tradit Chin Med. 2013;22(9):1596-7. Chinese.

23. Meng QJ, Zhang LF, Li GJ. [Therapeutic effect of Tanreqing on viral pneumonia in children]. Public Med Forum Mag. 2006;10(7):340-1. Chinese.

24. Li Q. [Therapeutic effect of Xiyanping on 90 cases of viral pneumonia]. J Ningxia Med Univ. 2009;31(6):781-2. Chinese.

25. Jia DM, Yang YJ. [Treatment of 60 cases of viral pneumonia in children with Tanreqing Injection]. Cent Plains Med J. 2006;33(4):69-70. Chinese.

26. Lv XH, Dong $\mathrm{CH}$, Zhu YH. Tanreqing injection in the treatment of children's viral pneumonia: observation of clinical efficacy. China Pharm. 2007;18(33):2611-2.

27. Xiong ZY, Liu J, Fu JP. [Efficacy and safety analysis of Reduning Injection in the treatment of viral pneumonia in children]. Contemp Med. 2017;23(11):116-7. Chinese.

28. Zhang XG, Han ZB, Han JX, Dong CH. [Therapeutic effect of Reduning Injection on 60 cases of viral pneumonia in children]. Qilu Pharm Aff. 2008;27(3):178-9. Chinese.

29. Jiang K, Tian QJ, Bao XH, Xu ZR. [Analysis and consideration of adverse drug reaction in traditional Chinese medicine injection]. Mod Med J China. 2021;23(4):93-8. Chinese.

30. Wu QG, Zhang XL, Song YP. [The current situation and outlet of traditional Chinese medicine injection]. Chin Foreign Med Res. 2019;17(36):185-8. Chinese.

31. Zhang XY, Lv L, Zhou YL, Xie LD, Xu Q, Zou XF, et al. Efficacy and safety of Xiyanping injection in the treatment of COVID-19: a multicenter, prospective, open-label and randomized controlled trial. Phytother Res. 2021;35(8):4401-10.

32. Huang WH, Teng LC, Yeh TK, Chen YJ, Lo WJ, Wu MJ, et al. 2019 novel coronavirus disease (COVID-19) in Taiwan: reports of two cases from Wuhan, China. J Microbiol Immunol Infect. 2020;53(3):481-4.

33. Shi H, Han X, Jiang N, Cao Y, Alwalid O, Gu J, et al. Radiological findings from 81 patients with COVID-19 pneumonia in Wuhan, China: a descriptive study. Lancet Infect Dis. 2020;20(4):425-34.

34. An SU. A reference to the original source of herb-acupuncture in methods. J Yakchim (Korean Herb-Acupuncture) Inst. 1997;1(1):87-102.

35. Song GE, Lim GM, Lee YG, Song GJ, Park SJ. A review of a clinical study on pharmacopuncture for insomnia in China. J Orient Neuropsychiatry. 2019;30(3):265-74.

36. Li H, Xiong N, Li C, Gong Y, Liu L, Yang H, et al. Efficacy of ribavirin and interferon- $\alpha$ therapy for hospitalized patients with COVID-19: a multicenter, retrospective cohort study. Int J Infect Dis. $2021 ; 104: 641-8$. 